\title{
Ectodermal dysplasia: A case report
}

\author{
Gayathri Devi M', Bakya Lakshmi K², Revathy V³, Preethy Chandran ${ }^{4}$ \\ From ${ }^{1}$ Final Year Post Graduate Student, ${ }^{2}$ Associate Professor, Department of Oral Medicine and Radiology, Tamilnadu Government Dental College \\ and Hospital ,Chennai, ${ }^{3}$ Assistant Professor, Department of Pedodontics, Tamil Nadu Government Dental College, ${ }^{4}$ Assistant Professor, Department \\ of Prosthodontics, Tamil Nadu Government Dental College, Chennai, Tamil Nadu, India
}

\begin{abstract}
Ectodermal dysplasia (ED) is a rare group of inherited disorders with defects in the development of one or more tissues derived from primary embryonic ectodermal derivatives. The inclusion of ED does not include all ectodermal derivatives and is manifested with a defect in skin, hair, teeth, and eccrine glands. Dry skin, frontal bossing, scanty eyebrows, and hair follicles are common features seen in these patients. The patient may suffer from high fever due to the absence of eccrine glands. Intraoral findings include a partial or complete absence of teeth with generalized spacing. It can be inherited or caused by a genetic mutation, and it can also happen without a family history. This case report presents a 12-year-old female child with hypohidrotic ED involving a multidisciplinary approach in ED that was beneficial both physiologically and psychologically is discussed in this case report.
\end{abstract}

Key words: Ectodermal dysplasia, Hyperthermia, Hypodontia, Oral rehabilitation, Removable prosthesis

$\mathrm{E}$ ctodermal dysplasia (ED) was first described by Thurman as a congenital, diffuse, non-progressive entity that occurs as a result of an ectodermal disturbance in the primitive stage of growth development [1]. Frequent phenotypic manifestation includes sparse hairs and deficiency of sweat glands. The common oral manifestations are anodontia or oligodontia, generalized spacing between teeth with malformation of teeth present in both deciduous and permanent dentition, and cleft lip and palate [2]. Other features include prominent supraorbital bridges, frontal bossing depressed nasal bridges, and hyperthermia. The patient often has unexplained fever as a result of loss of sweat glands. Based on the number and functioning of sweat glands, ED is classified as hypohidrotic ectodermal dysplasia (HED) also known as ChristSiemens-Touraine syndrome, which affects hair, nail, skin, and sweat glands and hidrotic ED, also known as Clouston syndrome which affects hair, nail, skin sparring the sweat glands [3].

\section{CASE REPORT}

A 12-year-old female came to the Department of Oral Medicine and Radiology with complaints of unerupted teeth and mastication difficulties. No similar condition was reported in her family members.

On examination, she had dry skin, sparse hairs and scanty eyebrows, broad supraorbital bridges, overfolding ears, saddle

\section{Access this article online}

Received - 06 January 2022

Initial Review - 15 January 2022

Accepted - 04 February 2022

DOI: $10.32677 /$ ijcr.v8i1.3329 nose, protuberant lips with perioral pigmentation, and normal nails on extra-oral inspection (Fig. 1). Intraorally, several teeth were missing $\quad(13,14,15,22,24,25,27,35,34,33,32,31,41,42,44,45,47)$. A high arched palate was noted (Fig. 2).

On radiological examination, panoramic radiograph revealed unerupted 13,18,25,37 and 47 (Fig. 3). Jaw growth was not impaired. The alveolar process did not develop favorably and the vertical dimension was reduced. Trichodentoosseous syndrome and partial anodontia were among the differential diagnosis. The case was provisionally diagnosed as ED based on clinical features, history of intolerance to high temperature, and radiographic examination.

The patient was motivated for prosthetic rehabilitation. Impressions were made and a removable partial denture has been delivered to the patient with the able guidance of prosthodontist and pedodontist (Fig. 4). This has improved her physiological and psychological status. She is on regular visits, and the patient was educated to avoid long-term activities and was explained about the genetic inheritance of this condition with appropriate counseling. Maybe in near future, she agrees to endosseous dental implants after the eruption of 13, 18,25 amd 47 .

\section{DISCUSSION}

Freire-Maia defined the nosologic group of ED as a pathogenic developmental defect with any group that exhibits at least two of

Correspondence to: Dr. Gayathri Devi M, Department of Oral Medicine and Radiology, Government Dental College and Hospital, Chennai, Tamil Nadu, India. E-mail: gayu18bds@gmail.com

(C) 2022 Creative Commons Attribution-NonCommercial 4.0 International License (CC BY-NC-ND 4.0). 
the following features: Trichodysplasia (abnormal hair), abnormal dentition, onchodysplasia (abnormal nails), and dyshidrosis (abnormal or missing sweat glands) [4]. The developmental disturbance also causes partial or complete absence of permanent or primary dentition. The partial (oligodontia) or complete absence of teeth (anodontia) in both primary and permanent

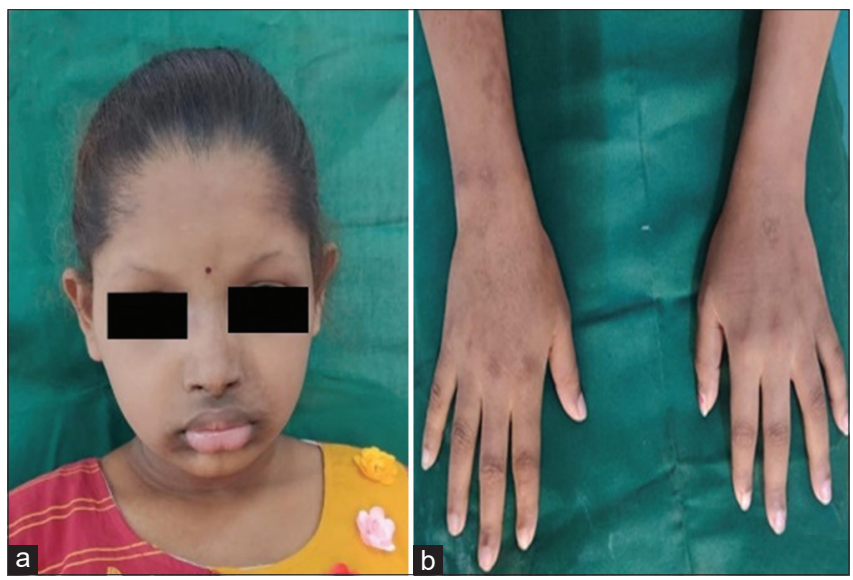

Figure 1: (a-b) Extraoral images presented with protuberant lips, scanty eyebrows, and normal nails

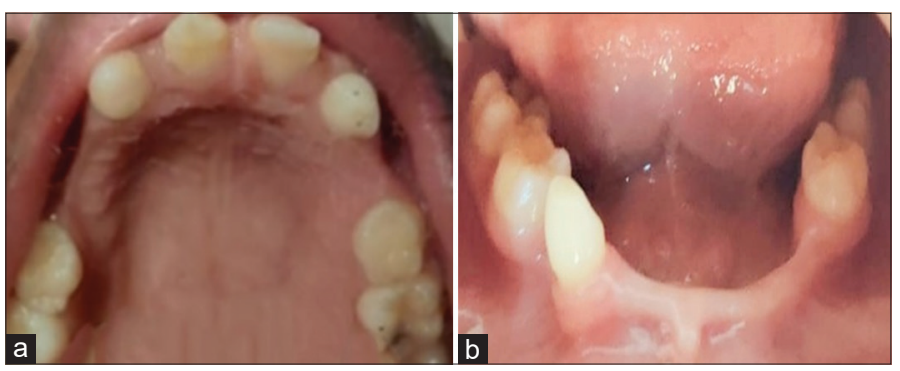

Figure 2: (a-b) Intraoral images presented with partial anodontia and altered crown morphology

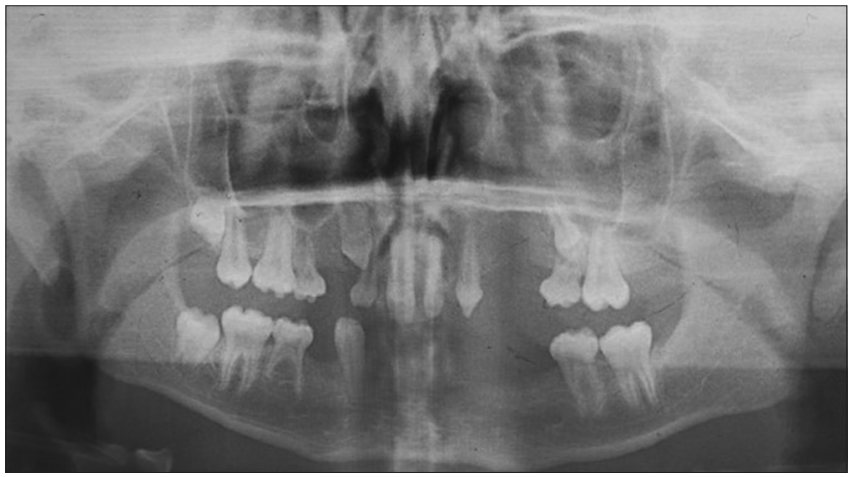

Figure 3: Panormic radiograph presenting unerupted 18, 13, 25 dentition is the most prominent feature. Apart from the number, the shape of the tooth is also altered, mainly conical in shape with that taurodontism is also seen in a few cases [5].

The clinical features include sparse, fine, lusterless hair with abnormal scalp texture, eyebrows and eyelashes, dry skin, nail defects, frontal bossing, depressed nasal bridge, and protuberant dry and cracked lips. Complete or partial absence of sweat glands can lead to dry skin and eczema, and there may be heat intolerance or hyperthermia in extreme weather conditions [5].

Mutations in genes that code for cell-cell communication, adhesion molecules, or transcription regulators may cause ED syndrome. The cause could be a mutation or deletion of specific genes, which can be inherited or happen in people who have no family history [6]. More than 300 cases studied genetically revealed that the $\mathrm{X}$-linked mode of inheritance, which has its gene locus at Xq11-21.1, is carried by the female but exhibited only in males [7]. ED is genetically related and the genes that control are EDA (ectodysplastin), EDARADD (ectodysplasin-receptor associated death domain), and EDAR (ectodysplasin receptor). ED can be autosomal dominant, autosomal recessive, or X-linked recessive [8]. Earlier research studies have found that mutations in the gap junction beta 6 (GJB6) gene, which codes for the protein connexin30 (CX30) are the most common cause of HED [9]. HED is characterized by syndromic tooth agenesis caused mostly by mutations in the ectodysplasin A (EDA), ectodysplasin A receptor (EDAR), EDARADD, and WNT10A genes. The triad symptoms of HED include hypohidrosis, hypotrichosis, and hypodontia [10]. Normal intelligence is observed [11]. Genetic alterations of ED-associated genes that only affect one derivative of ectoderm (e.g., hair, teeth, nails, and sweat glands) should be grouped as non-syndromic traits of the causative gene (e.g., non-syndromic hypodontia or missing teeth associated with pathogenic EDA variants) [12]. The patient in our study was not subjected to genetic analysis due to money constraints.

The most striking features in this case report are that the patient belong to HED and has a history of intolerance to hot environmental exposure with no genetic inheritance. She had dry skin, sparse hair and eyelashes, normal fingernails, and toenails, partial anodontia with altered tooth morphology. Missing teeth were more in the mandible than in the maxilla with maxillary hypoplasia. Skin biopsy and sweat pour test can be done to rule out hypohidrosis [13]. She was managed with a removable partial denture to create a positive self-image look which has improved her psychological status. She has planned for endosseous dental implants after the eruption of $13,18,25$ and 47 teeth.

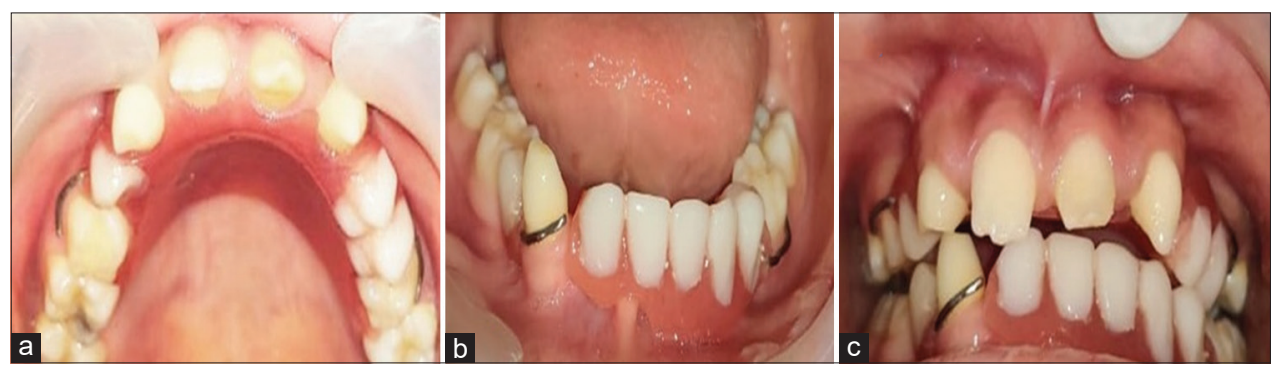

Figure 4: (a-c) Intraoral post-treatment images with removable prosthesis 


\section{CONCLUSION}

The physical and mental health of a person is affected by the clinical signs of ED. Through a multidisciplinary approach, the patient's speech, esthetics, and ability to eat a diverse diet have all improved and have the patient's acceptance among peers and family.

\section{REFERENCES}

1. Nunn JH, Carter NE, Gillgrass TJ, Hobson RS, Jepson NJ, Meechan JG, et al. The interdisciplinary management of hypodontia: Background and role of paediatric dentistry. Br Dent J 2003;194:245-51.

2. El-Tony MK, Feteih RM, Farsi J. Hereditary hypohidrotic ectodermal dysplasia with anodontia: A case report. Saudi Dent J 1994;6:31-4.

3. Mortier K, Wackens G. Ectodermal dysplasia anhidrotic. Orphanet Encyclopedia 2004;3:1-6.

4. Pigno MA, Blackman RB, Cronin RJ Jr., Cavazos E. Prosthodontic management of ectodermal dysplasia: A review of the literature. J Prosthet Dent 1996;76:541-5.

5. Dagrus K, Manjunatha BS, Shah V, Shah SN. Concomitant presence of ectodermal dysplasia with taurodontism: A rare entity. Ann Int Med Dent Res 2018;4:DE14-7.

6. Reyes-Reali J, Mendoza-Ramos MI, Garrido-Guerrero E, Méndez-Catalá CF, Méndez-Cruz AR, Pozo-Molina G. Hypohidrotic ectodermal dysplasia: Clinical and molecular review. Int J Dermatol 2018;57:965-72.
7. Itthagarun A, King NM. Ectodermal dysplasia: A review and case report. Quintessence Int 1997;28:595-602.

8. Zhan Y, Luo S, Pi Z, Zhang G. A recurrent mutation of GJB6 in a big Chinese family with Hidrotic ectodermal dysplasia. Hereditas 2020;157:1-4.

9. Lamartine J, Essenfelder GM, Kibar Z, Lanneluc I, Callouet E, Laoudj D, et al. Mutation in GJB6 causes hidrotic ectodermal dysplasia. Nat Genet 2000;26:142-4.

10. Ranjan P, Das P. Understanding the impact of missense mutations on the structure and function of the EDA gene in X-linked hypohidrotic ectodermal dysplasia: A bioinformatics approach. J Cell Biochem 2021. Doi: 10.1002/ jcb.30186

11. Crawford PJ, Aldred MJ, Clarke A, Tso MS. Rapp-Hodgkin syndrome: An ectodermal dysplasia involving the teeth, hair, nails, and palate. Oral Surg Oral Med Oral Pathol 1989;67:50-62.

12. Wright JT, Fete M, Schneider H, Zinser M, Koster MI, Clarke AJ, et al. Ectodermal dysplasias: Classification and organization by phenotype, genotype and molecular pathway. Am J Med Genet A 2019;179:442-7.

13. Taieb A. X-linked hypohidrotic ectodermal dysplasia in the new born: A diagnostic challenge. Eur J Pediatr Dermatol 1998;8:201-4.

Funding: None; Conflicts of Interest: None Stated.

How to cite this article: Devi MG, Lakshmi KB, Revathy V, Chandran P. Ectodermal dysplasia: A case report. Indian J Case Reports. 2022;8(1):19-21. 